\title{
BEING METRIC-WISE: HETEROGENEITY IN BIBLIOMETRIC KNOWLEDGE
}

\author{
Saber sobre métricas: heterogeneidad en el \\ conocimiento bibliométrico
}

\section{Sandra Rousseau and Ronald Rousseau}

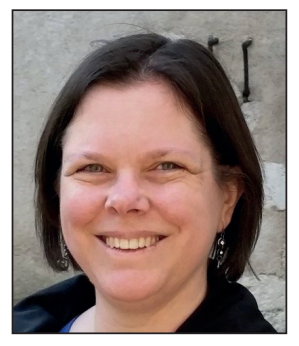

Sandra Rousseau has a PhD in Economics (2005) from the KU Leuven where she is an associate professor at the Faculty of Economics and Business. She teaches environmental economics and research methods. Her research focusses on the design, implementation and evaluation of environmental policy as well as on the evaluation of research activities.

http://orcid.org/0000-0001-8948-8644

KU Leuven, Faculty of Economics and Business Warmoesberg 26. B-1000 Brussel, Belgium sandra.rousseau@kuleuven.be

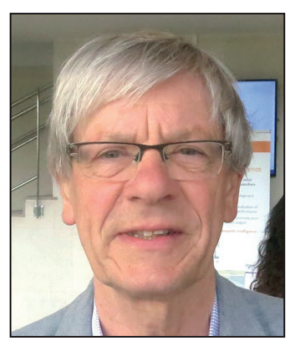

Ronald Rousseau is the former president of the International Society for Scientometrics and Informetrics (ISSI). He is a guest researcher at $K U$ Leuven and the University of Antwerp and a honorary professor at Zhejiang University and Henan Normal University. He is the recipient of the Derek J. de Solla Price award for scientometrics (2001) and co-author of Introduction to informetrics (with Leo Egghe, 1990).

http://orcid.org/0000-0002-3252-2538

KU Leuven, Dept. of Mathematics Celestijnenlaan, 200B. B-3001 Leuven, Belgium University of Antwerp (UA), Faculty of Social Sciences Middelheimlaan, 1. B-2020 Antwerp, Belgium ronald.rousseau@kuleuven.be ronald.rousseau@uantwerpen.be

\section{Abstract}

While general publication practices clearly differ between disciplines, knowledge about scientometric indicators can also greatly vary. The observed heterogeneity in bibliometric knowledge inspired us to define the concept of 'metric-wiseness' for researchers. Being metric-wise can lead to an advantage for knowledgeable researchers over uninformed colleagues, even when they are of otherwise equal competence. We identify two paths through which metric-wiseness can play a role and lead to behavioural changes in the research process. As a first path, metric-wiseness can be seen as an additional tool that is useful in reporting one's research portfolio. A second one is more ambiguous and has some undesirable aspects, possibly diminishing intrinsic motivational factors for doing research. Innovation and innovative research slows down if crowding out happens due to an excessive attention to scientometric indicators. We propose an approach to actually measure metric-wiseness.

\section{Keywords}

Research evaluation; Academic auditing; Metric-wiseness; Researchers' motivation; Scientometric indicators; Bibliometrics.

\section{Resumen}

Aunque las prácticas generales de publicación difieren claramente entre las disciplinas, el conocimiento sobre los indicadores cienciométricos también puede variar considerablemente. La heterogeneidad observada en el conocimiento bibliométrico nos inspiró a definir el concepto de 'sabiduría-métrica' para los investigadores. Ser métrico-sabio puede representar una ventaja para los investigadores expertos sobre los colegas desinformados. Identificamos dos caminos a través de los cuales el conocimiento de las métricas puede desempeñar un papel y conducir a cambios de comportamiento en el proceso de investigación. Como primer camino, tales conocimientos pueden ser vistos como una herramienta adicional, útil en la presentación de informes de investigación. El segundo camino es más ambiguo y tiene algunos aspectos indeseables, que posiblemente hagan disminuir los factores motivacionales intrínsecos para investigar. La innovación y la investigación innovadora se ralentizan si se produce un excesivo desplazamiento de la atención hacia los indicadores cientométricos. Proponemos un enfoque para medir realmente la sabiduría métrica.

\section{Palabras clave}

Evaluación de la investigación; Auditoría académica; Conocimiento de las métricas; Motivación de los investigadores; Indicadores cientométricos; Cienciometría; Bibliometría. 
Rousseau, Sandra; Rousseau, Ronald (2017). "Being metric-wise: Heterogeneity in bibliometric knowledge". El profesional de la información, v. 26, n. 3, pp. 480-487.

https://doi.org/10.3145/epi.2017.may.14

\section{Introduction}

Working in interdisciplinary research centres, some observations drew our attention. While general publication practices clearly differ between disciplines, knowledge about scientometric indicators also greatly varies among colleagues. Some colleagues are not only familiar with popular indicators such as the Garfield-Sher journal impact factor or the Hirsch-index, but are also familiar with more sophisticated indicators such as Eigenfactor scores (Bergstrom, 2007; Bergstrom; West; Wiseman, 2008) and the SCImago Journal Rank (SJR) (González-Pereira; Guerrero-Bote; DeMoya-Anegón, 2010). Others, on the other hand, do not even know how to find the ISI impact factor of a journal, let alone how to define it. Even though knowledge of scientometric indicators does not imply anything about the quality of the research performed by these colleagues, it may have an impact on how their research portfolio is presented and perceived by selection committees or funding agencies.

The knowledge of scientometric indicators may have an impact on how researchers' portfolio is presented and perceived by selection committees or funding agencies

In order to have an idea about the general knowledge about scientometric indicators we distributed an online survey among all members of the International Association of Agricultural Economists (IAAE) by email in February 2015. We obtained 138 complete answers out of the 161 responses that we received. Since the IAAE has 635 members in 2015, we have a response rate of $25 \%$ (161/635). These respondents included $22 \%$ female researchers, $33 \%$ researchers older than 55 , $64 \%$ were affiliated to a university or a university college, $20 \%$ published more than five journal articles in 2013 and 2014 and 6\% published more than ten journal articles in 2013 and 2014. Looking at their current residence, $31 \%$ of the respondents was living in Europe, $26 \%$ in North America, $16 \%$ in Africa, $12 \%$ in South America, $12 \%$ in Asia and $3 \%$ in Australia.

In the survey respondents were asked about their knowledge concerning the following indicators:
- ISI journal impact factor (Web of Science)

- SCImago journal rank (Scopus)

- 5-year synchronous journal impact factor (Web of Science)

- Hirsch-index (h-index)

- Eigenfactor score (Web of Science)

- Source normalized impact per paper (SNIP) (Scopus)

They could select one of four categories:

- I do not know this indicator.

- I know this indicator (but not its meaning and its calculation).

- I know this indicator and its meaning (but not how it is calculated).

- I know this indicator, its meaning and calculation.

The results show that respondents' knowledge concerning these scientometric indicators was quite varied (see figure 1). As could be expected, the ISI journal impact factor was the best known indicator, followed by the Hirsch-index, while the SNIP and the Eigenfactor score were among the least known. Surprisingly some $10 \%$ of the respondents were not familiar with the ISI journal impact factor and $40 \%$ had never heard of the Hirsch-index.

This pilot study suggests that knowledge about indicators is quite heterogeneous among researchers. An unpublished survey by Springer Nature (Penny, 2016) points to the same conclusion. These findings inspired us to explore the possible implications of this variable degree of knowledge about bibliometric indicators on researchers and research activities. To this end, we define the concept of metric-wiseness and explore its implications for researchers and research. In addition, we investigate how researchers' knowledge of and attitudes towards bibliometric indicators can be measured. 
This initial exploration provides a stepping stone towards future empirical studies as well as an invitation to assess the desirable characteristics of a metric of metric-wiseness.

This article is subdivided as follows. In the next section we introduce the term metric-wiseness. Then, we briefly discuss how metric-wiseness influences the research process. Next we discuss the influence of being metric-wiseness on a researcher's environment. Before coming to a conclusion we propose a methodology to measure this new concept. The contents of this article have been presented during the $20^{\text {th }}$ International Conference on Science and Technology Indicators (2-4 September 2015, Lugano, Switzerland). Since then the article has been considerably expanded and revised.

Knowledge about indicators is quite heterogeneous among researchers

\section{Metric-wiseness}

These observed differences in bibliometric knowledge among colleagues inspired us to define the concept of 'metric-wiseness' for researchers as:

"a researcher's capacity to use the characteristics and formats of scientometric indicators to present one's true research value" (Rousseau; Rousseau, 2015).

This definition consists of two parts: one aspect is knowing the existence, mathematical definition and logical implications of scientometrics indicators; while the second one is knowing their proper use.

The term 'metric-wiseness' is based on the related concept of 'test-wiseness'. As stated by Millman, Bishop and Ebel (1965, p. 707),

"test-wiseness is defined as a subject's capacity to utilize the characteristics and formats of the test and/or the test taking situation to receive a high score. Testwiseness is logically independent of the examinee's knowledge of the subject matter for which items are supposedly measures."

Similar to test-wiseness, metric-wiseness is logically inde- pendent of the researcher's scientific capacities regarding his/her subject matter for which the indicators supposedly measure. Thus a researcher can be metric-wise or not. However, being or not being metric-wise does not depend on the quality of that researcher in his or her field. Note that this assumption does not hold for scientometric or informetric researchers whom we assume to be metric-wise by default.

Being metric-wise could lead to an advantage for knowledgeable researchers over uninformed colleagues, even when they are of otherwise equal competence. This would lead to a situation where certain researchers or research teams advance faster (e.g., due to better access to funding) than others. Combined with a Matthew effect (Merton, 1968; Mahbuba; Rousseau, 2011), this situation would then continue to exist over time.

While defining metric-wiseness, we explicitly distinguish knowledge and use of indicators by researchers from the knowledge and use of indicators by evaluators. In this contribution we focus on the first aspect. The second aspect, indicator use by evaluators, has received relatively more attention and has led to actions such as the Declaration on research assessment (DORA declaration) (DORA, 2012) and the Leiden manifesto (Hicks et al., 2015).

\section{Influence of metric-wiseness on the research process}

Looking at the schematic representation of the research process in Figure 2, we can distinguish two separate sub-processes in the research process, namely performing research, on the one hand, and reporting research, on the other. Firstly, the decision of doing research and what type of research to pursue is determined by intrinsic motivational factors such as intellectual curiosity, the feeling that one is able to find a result, the pleasure to write, or a desire to create benefits to society, as well as extrinsic factors such as a desire to increase one's standing, to avoid failure or to obtain funding (Deci; Koestner; Ryan, 2001; Deemer; Martens; Buboltz, 2010; Hardré et al., 2011; Lach; Schankerman, 2008). Secondly, the portfolio of research activities is then reported deliberately (for example, in a CV) or accidentally (for example, as information available on Google Scholar) to the outside world. Communication of research activities is needed when applying for a new job, for funding or for promotion. It is now possible to identify two paths through which metric-wiseness can, jointly or separately, play a role and lead to behavioural changes. The first one is, in our opinion, highly desirable, while the second one is more ambiguous and has some undesirable aspects.

As a first path, metric-wiseness can be seen as an additional tool that is useful in reporting one's research portfolio. For example, it 
may be interesting to include journal indicators and citation counts from Scopus besides those from the Web of Science (WoS) due to the larger coverage and the inclusion of 'in press' articles from Elsevier. Moreover, it is useful to know that Google Scholar records citation counts and indices for non-English publications (often one's mother tongue) and even working papers (Aguillo, 2011; Amara; Landry, 2012; De-Winter; Koestner; Ryan, 2014). This aspect is of particular importance for many colleagues performing research in the Social Sciences and in the Arts and Humanities. For colleagues working in technical fields patents and patent citations should not be forgotten. Similarly, usage data, such as those provided in the Web of Science or collected via a local Counter account, may show the total amount of (general or local) interest aroused by researchers who do not work in citation-intensive fields. Besides mentioning countbased results, it is for these scholars necessary to indicate if the journals or books they use to disseminate their findings are peer-reviewed. In several regions and countries peerreview is an essential requirement for research output to be included in the set of publications which leads to research funding. This is the case, for example, in Norway (Sivertsen, 2010) and Flanders (Engels; Ossenblok; Spruyt, 2012). Furthermore, knowing how to make and adapt one's ResearcherID, Orcid ID or Google Scholar account can save not only time for researchers themselves, but also allows other parties to easily identify work by the same researcher. Name disambiguation is often a challenge, especially for researchers with frequently occurring names. In times when even the Nature Index pays attention to altmetric results (Campbell; Grayson, 2014), it certainly pays to take the social media aspect of one's research into account. The last decade has also seen the growth of academic research networks such as ResearchGate or Mendeley as a useful way to communicate about research. These research networks typically communicate usage and bibliometric indicators to their participants, although these metrics are not always easy to understand. Consider, for example, the lack of a clear definition of a researcher's $R G$ score in ResearchGate:

http://www.researchgate.net/publicprofile.RGScoreFAQ. html

Metric-wiseness can be seen as an additional tool that is useful in reporting one's research portfolio

As a final example, it may also benefit a researcher to know how errors and omissions in databases such as the Web of Science can be corrected.

A second path through which metric-wiseness can change the research process is by influencing the relative weight associated with intrinsic and extrinsic research motivations. This change of balance may possibly lead to a crowding out of intrinsic motivational factors for doing research.

Thus, research topics and publication avenues are no longer selected out of a desire to increase the universal pool of knowledge, to advance science or to reach the most interested audience, but to maximize a researcher's bibliome- tric indicator levels. In this way, it becomes interesting to have several co-authors rather than publish as sole author. Moreover, only publications in journals with a high impact factor are worthwhile, while writing in other languages besides English is pointless (so the argument goes). Finally, it may also be tempting to make informal agreements with colleagues to 'help' each other to increase citations or to manipulate indicators such as the $h$-index, see Bartneck and Kokkelmans (2011). We should mention though that the fact alone of knowing that one will be evaluated may already lead to a change in behaviour. This can be described as a kind of Hawthorne effect, namely a type of reaction in which individuals modify or improve an aspect of their behaviour in response to their awareness of being observed (Adair, 1984). More in the context of research evaluation we mention the law of Goodhart (1975) which states that when a feature is picked as an indicator it ceases to function as an indicator because people start to game it.

With metric-wiseness, research topics and publication avenues could be selected to maximize a researcher's bibliometric indicator levels

Stimulating research activities and results that help to obtain the institutional goals is one of the major aims of all forms of academic auditing. Here we can distinguish two aspects: the first leading to institutional benefits, but a second one may lead to stereotypical research, namely that type that is most valued by short-term goals. A recent review on the effects of indicators can be found in (De-Rijcke et al., 2015).

\section{Impact of and possible reactions to metric- wiseness}

The two paths through which metric-wiseness affect research and researchers lead to a set of markedly different impacts. Firstly, the presence of metric-wiseness as another tool in the researcher's toolbox besides presentation and communication skills seems to be a beneficial evolution. It levels the playing field and provides a clearer picture of a researcher's quality. If every scientist would become metricwise the assessment processes that are part of researchers' life would potentially be less distorted and the advantage of more knowledgeable researchers would be reduced. As such we think that a basic knowledge of informetrics, including knowledge of scientometrics indicators and data sources, should be part of any doctoral education.

However, the evolution that metric-wiseness could lead to a crowding out of other, intrinsic, motivations for doing research is clearly less desirable. Metric-wiseness can magnify the adverse effects associated with the 'publish or perish' culture. As such metric-wiseness can worsen a number of undesirable practices such as undertaking trivial studies because they yield rapid results, reporting research in parts rather than as a whole (salami slicing), duplicate publishing, honorary authorship, and even plagiarism and scientific fraud (Abelson, 1990; Hartemink, 2000; Van-Dalen; Henkens, 
2012). Researchers can also act strategically in academic research networks and may focus on influencing metrics within such networks (Hammarfelt; De-Rijcke; Rushforth, 2016; Orduña-Malea; Martín-Martín; Delgado-López-Cózar, 2016). In addition, these behavioural effects imply that researchers prefer well-established journals over new journals and certainly over conference proceedings. Such strategic behaviour slows down the distribution of research findings and the evolution of scientific communication channels. Moreover, innovation and innovative research slows down if crowding out happens due to an excessive attention to scientometric indicators. In this context, Markusova et al. (2009) warn against indiscriminate introduction of quantitative indicators for science policy applications.

\section{A basic knowledge of informetrics, inclu- ding knowledge of scientometrics indi- cators and data sources, should be part of any doctoral education}

Overall, we can distinguish four different expressions of a researcher's metric-wiseness:

- being ignorant;

- using indicators;

- misusing indicators; and

- moving beyond indicators (see Figure 3).

Beginning master or doctoral students are usually ignorant regarding the meaning and use of scientometric indicators and hence cannot be metric-wise. Thus a minimum requirement of being metric-wise is to be able to recognize (a set of) indicators and to be able to describe their meaning in laymen's terms. However, this is only a first step; a researcher's knowledge can be extended and deeper insight into indicators and their proper use can be obtained. While basic knowledge of indicators can only lead to a basic use of these indicators by a researcher, a deeper knowledge can lead to both use and misuse of indicators and can lead to crowding out effects. Finally, an established researcher can take an even broader viewpoint and can look beyond indicators as measures of research quality. Such researchers are only driven by scientific or social interest and know that in the end success, including those aspects measured by indicators, will come. They do not care if their articles or other research results are -hopefully temporarily- undercited or underused. As an illustration of how researchers can move beyond the (mis)use of indicators, we would like to recall the main points of the DORA declaration (DORA, 2012). This declaration has been signed by many scientists, representing major international and national research organizations. Its main recommendations include:

- elimination of journal-based metrics in funding;

- appointment and promotion considerations of individuals;

- assessing research on its own merits, rather than on the journal in which it was published; and

- taking opportunities provided by electronic publishing into account, including new socially-related indicators.
Throughout their career paths researchers can express their metric-wiseness through different trajectories. Obviously we all start as ignorant individuals. Later researchers can opt to use indicators for communicating about their research and then decide that bibliometric indicators are imperfect communication tools. Or they can decide to misuse indicators to select those publications that increase their likelihood of being promoted or of receiving funding throughout their whole career. There is no obvious logical or temporal sequence in going through the different expressions of metric-wiseness and many different trajectories can be considered.

\section{Innovation and innovative research slows down if crowding out happens due to an excessive attention to scientome- tric indicators}

Next we would like to note that, due to the multi-faceted nature of metric-wiseness, it is not a priori clear how institutions or evaluators should react. As long as metric-wiseness is seen as a tool to improve communication about a researcher's portfolio, it is beneficial to stimulate knowledge of bibliometric indicators among researchers. For instance, it may be interesting to inform doctoral researchers on the what and how of the most frequently used indicators.

When metric-wiseness leads to a crowding out effect, reducing intrinsic motivations, it should clearly be counteracted. This is however not always easy to achieve. A well-known, but time-consuming, approach is to use not only quantitative measures for the assessment of researchers, but also qualitative measures and to include peers in the process. Another option is to look for mechanisms to detect strategic behaviour driven by a desire to manipulate bibliometric indicators. For instance, Bartneck and Kokkelmans (2011) introduce the $q$-index as a means to detect how strategically an author uses self-citations to manipulate the $h$-index. As a final suggestion, journal editors and those colleagues involved in academic auditing, may abolish the notion of author-

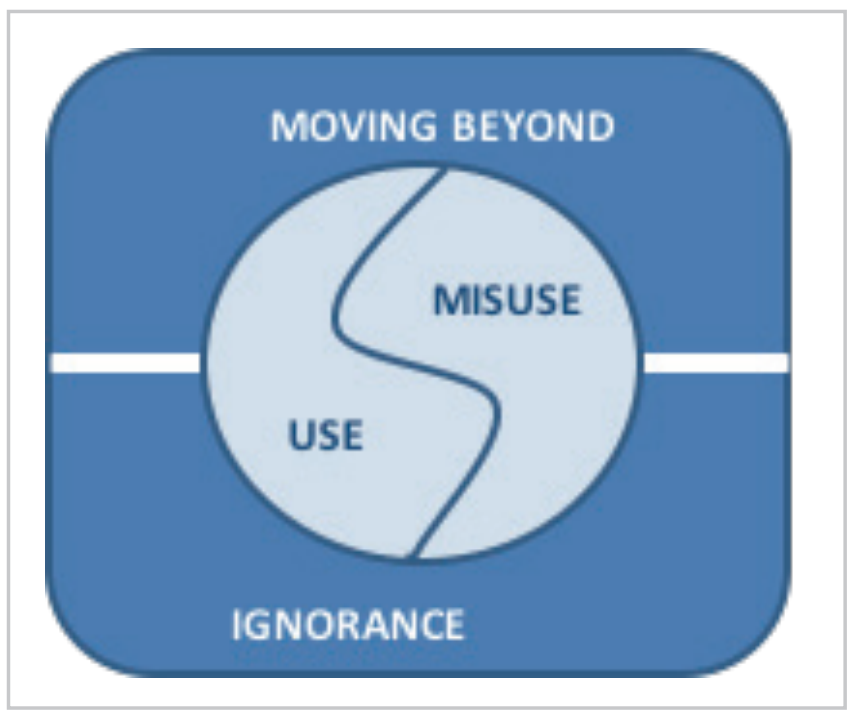

Figure 2. Simplified representation of the research process 
ship, and replace it by the notion of contributor, implying a continuum of activities (Rennie; Yank, 1998). But, clearly also this may lead to strategic behaviour and game playing.

\section{How to measure metric-wiseness}

In view of the above considerations we propose a two-levelled approach to measure metric-wiseness. On a first level one just asks if the respondent is familiar with the concept of one or more popular indicators such as a journal impact factor. Specifically, one could ask if a researcher can give the definition of the indicator (no 'technical' details are expected; an answer like 'it is a journal's average number of citations per publication' is surely sufficient), and if he/she can give one more example of a publication-citation metric (for an individual, a group of individuals or for a journal, this does not matter). A person who can answer these questions correctly is then said to be metric-wise.

On a second level, we would like to identify the manner through which this metric-wiseness is expressed. To this end, we propose to use a multidimensional Likert-scale with several statements trying to measure four dimensions regarding indicators:

- technical knowledge

- use of indicators

- intrinsic motivation

- external pressure.

The first two aspects aim to measure the degree of metricwiseness of a researcher. The technical dimension measures the extent to which respondents have in-depth knowledge of indicators, are able to influence indicators and so on. In addition we are also interested in respondents' view on the manner in which indicators should be used or not be used. The next two aspects aim to identify the impact of indicators as perceived by researchers when doing and reporting their research. The external dimension measures the extent to which respondents are forced by their institution, fun- ding agencies, colleagues or co-authors to take bibliometric indicators into account in their research and publication activities. The intrinsic dimension, on the other hand, measures the extent to which respondents believe in indicators as quality measures as well as their willingness to go beyond indicators.

In Table 1 we present some suggestions of statements that can be used in such as multidimensional scale to identify the expression of metric-wiseness preferred by a researcher. For each of these statements a respondent is asked to present their opinion on a five points scale going from 1 - 'I completely agree with this statement' to 5 - 'I completely disagree with this statement. These are only suggestions and future research will be needed to develop a valid and reliable scale measuring the expressions of metric-wiseness.

\section{Conclusion}

The concept of metric-wiseness can be used to identify the different degrees of scientometric knowledge that researchers may possess. Scientometric knowledge can lead to strategic changes in researchers' behaviour. Therefore, the degree of metric-wiseness can influence researchers' relative performance perceived by evaluation committees. As a trajectory, metric-wiseness can move through four different phases: ignorance, use of indicators, misuse of indicators and moving beyond indicators.

Like many other concepts such as intelligence, diversity, relevance, etc., metric-wiseness is an idea that can only be made precise by a concrete measurement procedure, and surely, like for the above mentioned concepts many more or less acceptable procedures with subtle, or not so subtle, differences can be imagined. It would therefore be interesting for future researchers to develop an adequate measure of metric-wiseness and to test it in a variety of settings. Metric-wiseness of researchers can depend on researchers' personal characteristics, on the institutional and regulatory

Table 1. Examples of test questions for metric-wiseness

\begin{tabular}{|c|c|}
\hline & Suggested statements \\
\hline Technical dimension & $\begin{array}{l}\text { On average older researchers have higher } h \text {-indices. } \\
\text { Bibliometric indicators can easily be compared across disciplines. } \\
\text { Open access journals never have a Garfield-Sher impact factor. } \\
\text { Citations received in conference proceedings are included in an article's total number of received citations. }\end{array}$ \\
\hline Use of indicators & $\begin{array}{l}\text { A purely bureaucratic/automatic and quantitative approach to research evaluation is best for an individual researcher. } \\
\text { The quality of a researcher should be measured in relative terms within a field rather than in absolute terms. } \\
\text { Besides citation-based indicators one must, in applied fields, also take patent-based and similar indicators into account. } \\
\text { The social influence of research must be taken into account. }\end{array}$ \\
\hline Intrinsic dimension & $\begin{array}{l}\text { I select topics for research based on their potential to advance science. } \\
\text { If I do not have the expertise to solve a particular problem, I do not hesitate asking a colleague to collaborate with me. } \\
\text { I select research problems inspired by my own curiosity. }\end{array}$ \\
\hline External dimension & $\begin{array}{l}\text { I feel completely free to publish my research in any way I want. } \\
\text { My institution influences what my research is about. } \\
\text { My institution influences how I communicate the results of my research. } \\
\text { My likelihood of being promoted depends only on the number of articles published in journals indexed in the Web of } \\
\text { Science. } \\
\text { It is important to use social media (Twitter, blogs...) to distribute the results of my research. } \\
\text { It is important to use academic research networks (Mendeley, ResearchGate...) to distribute the results of my research. } \\
\text { My likelihood of being promoted depends mainly on the number of articles of which I am first or corresponding author. }\end{array}$ \\
\hline
\end{tabular}


settings as well as on the discipline in which a researcher is active.

Moreover, one could wonder if metric-wiseness should be considered a theoretical concept or one that can be derived from actual behaviour. The difference may be illustrated by the fact that even very intelligent persons can sometimes act unwisely in matters outside their area of expertise (scientifically intelligent is not the same as emotionally intelligent). The conceptual development of metric-wiseness is another interesting challenge for future research.

As also colleagues acting as panel members in peer review exercises should be metric-wise, we would like to point out that scientometric indicators, including synthetic ones, are never completely correct and at best probably approximately correct (PAC) (Rousseau, 2016). This implies that members of evaluation committees must realize the importance of including qualitative aspects in academic auditing. When performing their mission they should be able to spend a sufficient amount of time checking different portfolios; this further implies large enough budgets for evaluation. A purely bureaucratic and quantitative approach can never be beneficial for individual scientists and science in general.

Somewhat surprisingly it seems that large groups of colleagues are almost "illiterate" when it comes to indicators. For this reason, we strongly encourage all thesis advisors to include a basic course on scientometrics/informetrics in the doctoral dissertation package so that being metric-wise belongs to the set of key competencies that any doctoral student must master.

\section{Acknowledgements}

The authors thank their colleagues Raf Guns (UAntwerpen), Tim Engels (UAntwerpen), Eline Poelmans (KU Leuven), Jo Swinnen (KU Leuven) as well as an anonymous referee for their suggestions and help with data collection.

\section{Bibliography}

Abelson, Philip (1990). "Mechanisms for evaluating scientific information and the role of peer review". Journal of the American Society for Information Science, v. 41, n. 3, pp. 216-222.

https://doi.org/10.1002/(SICI)1097-4571(199004)41:3\%3C216::AIDASI13\%3E3.0.CO;2-6

Adair, John G. (1984). "The Hawthorne effect: A reconsideration of the methodological artifact". Journal of applied psychology, v. 69, n. 2, pp. 334-345.

https://doi.org/10.1037/0021-9010.69.2.334

Aguillo, Isidro F. (2011). "Is Google Scholar useful for bibliometrics? A webometric analysis". In: Noyons, Ed; Ngulube, Patrick; Leta, Jacqueline (eds.). Proceedings of the ISSI 2011 conf., pp. 19-25. ISBN: 9789081752701

Amara, Nabil; Landry, Réjean (2012). "Counting citations in the field of business and management: Why use Google Scholar rather than the Web of Science". Scientometrics, v. 93, n. 3, pp. 553-581.

https://doi.org/10.1007/s11192-012-0729-2

Bartneck, Christoph; Kokkelmans, Servaas (2011). “Detec- ting h-index manipulation through self-citation analysis". Scientometrics, v. 87, n. 1, pp. 85-98. https://doi.org/10.1007/s11192-010-0306-5

Bergstrom, Carl T. (2007). "Eigenfactor: measuring the value and prestige of scholarly journals". College \& research libraries news, v. 68 , n. 5, pp. 314-316.

http://crln.acrl.org/content/68/5/314.full.pdf+htm/

Bergstrom, Carl T.; West, Jevin D.; Wiseman, Marc A. (2008). "The Eigenfactor ${ }^{\mathrm{TM}}$ metrics". Journal of neuroscience, v. 28, n. 45, pp. 11433-11434.

https://doi.org/10.1523/JNEUROSCI.0003-08.2008

Campbell, Nick; Grayson, Michelle (2014). “Index 2014 global". Nature, v. 515, n. 7526, p. S49.

https://doi.org/10.1038/515S49a

De-Rijcke, Sarah; Wouters, Paul F.; Rushforth, Alex D.; Franssen, Thomas P.; Hammarfelt, Björn (2016). "Evaluation practices and effects of indicator use. A literature review". Research evaluation, v. 25, n. 2, pp. 161-169.

https://doi.org/10.1093/reseval/rvv038

De-Winter, Joost C. F.; Zadpoor, Amir A.; Dodou, Dimitra (2014). "The expansion of Google Scholar versus Web of Science: A longitudinal study". Scientometrics, v. 98, n. 2, pp. 1547-1565.

https://doi.org/10.1007/s11192-013-1089-2

Deci, Edward L.; Koestner, Richard; Ryan, Richard M. (2001). "Extrinsic rewards and intrinsic motivation in education: Reconsidered once again". Review of educational research, v. 71, n. 1, pp. 1-27.

https://selfdeterminationtheory.org/SDT/documents/2001_ DeciKoestnerRyan.pdf

https://doi.org/10.3102/00346543071001001

Deemer, Eric D.; Martens, Matthew P.; Buboltz, Walter C. (2010). "Toward a tripartite model of research motivation: Development and initial validation of the research motivation scale". Journal of career assessment, v. 18, n. 3, pp. 292-309. https://goo.gl/2zr2ZN

https://doi.org/10.1177/1069072710364794

DORA (2012). San Francisco declaration on research assessment.

http://www.ascb.org/files/SFDeclarationFINAL.pdf

Engels, Tim C. E.; Ossenblok, Truyken L. B.; Spruyt, Eric H. J. (2012). "Changing publication patterns in the social sciences and humanities, 2000-2009". Scientometrics, v. 93, n. 2, pp. 373-390.

https://goo.gl/O9ZEPt

https://doi.org/10.1007/s11192-012-0680-2

González-Pereira, Borja; Guerrero-Bote, Vicente P.; DeMoya-Anegón, Félix (2010). "A new approach to the metric of journals' scientific prestige: The SJR indicator". Journal of informetrics, v. 4, n. 3, pp. 379-391.

https://goo.gl/C1v1Sb

https://doi.org/10.1016/j.joi.2010.03.002

Goodhart, Charles A. E. (1975). “Problems of monetary management: The UK experience". In: Goodhart, Charles A. E. Monetary theory and practice. The UK experience. Papers in 
monetary economics, v. 1. Sydney: Reserve Bank of Australia, pp. 91-121. ISBN: 9780333360606

Hammarfelt, Björn; De-Rijcke, Sarah; Rushforth, Alexander D. (2016). "Quantified academic selves: The gamification of research through social networking services". Information research, v. 21, n. 2, paper SM1.

http://InformationR.net/ir/21-2/SM1.htm/

Hardré, Patricia L.; Beesley, Andrea D.; Miller, Raymond L.; Pace, Terry M. (2011). "Faculty motivation to do research: Across disciplines in research-extensive universities". Journal of the professoriate, v. 5, n. 1, pp. 35-69.

https://www.missouristate.edu/assets/longrangeplan/Faculty Motivation_to_Do_Research.pdf

Hartemink, Alfred E. (2000). "Publish or perish (3) - Fraud and ethics". Bulletin of the International Union of Soil Sciences, v. 97, pp. 36-45.

http://www.alfredhartemink.nI/PDF/3.\%20Fraud\%20 and\%20ethics.pdf

Hicks, Diana; Wouters, Paul; Waltman, Ludo; De-Rijcke, Sarah; Rafols, Ismael (2015). "The Leiden Manifesto for research metrics". Nature, v. 520, n. 7548, pp. 429-431. https://doi.org/10.1038/520429a

Lach, Saul; Schankerman, Mark (2008). "Incentives and invention in universities". RAND journal of economics, v. 39, n. 2, pp. 403-433.

http://eprints.Ise.ac.uk/4711/1/Incentives_and_Invention_ in_Universities.pdf

https://doi.org/10.1111/j.0741-6261.2008.00020.x

Mahbuba, Dilruba; Rousseau, Ronald (2011). "The Matthew effect and a relation with concept symbols and defaults". Annals of library and information studies, v. 58, n. 4, pp. 335-345.

http://nopr.niscair.res.in/bitstream/123456789/13483/1/ ALIS\%2058(4)\%20335-345.pdf

Markusova, Valentina A.; Jansz, Margriet; Libkind, Alexandr N.; Libkind, Ilya; Varshavsky, Alexander (2009). "Trends in Russian research output in post-Soviet era". Scientometrics, v. 79, n. 2, pp. 249-260.

https://doi.org/10.1007/s11192-009-0416-0

Merton, Robert K. (1968). "The Matthew effect in science". Science, v. 159, n. 3810, pp. 56-63.

http://www.garfield.library.upenn.edu/merton/matthew1. $p d f$ https://doi.org/10.1126/science.159.3810.56

Millman, Jason; Bishop, Carol H.; Ebel, Robert (1965). “An analysis of test-wiseness". Educational and psychological measurement, v. 25, n. 3, pp. 707-726.

https://goo.gl/OFaPOm

https://doi.org/10.1177/001316446502500304

Orduña-Malea, Enrique; Martín-Martín, Alberto; DelgadoLópez-Cózar, Emilio (2016). "Metrics in academic profiles: a new addictive game for researchers?". Revista española de salud pública, v. 90, e1-e5.

https://goo.gl/xyrqkr

Penny, Dan (2016). What matters where? Cultural and geographical factors in science (slide 21).

https://dx.doi.org/10.6084/m9.figshare.3969012.v1

Rennie, Drummond; Yank, Veronica (1998). "If authors became contributors, everyone would gain, especially the reader". American journal of public health, v. 88, n. 5 , pp. 828-830.

https://doi.org/10.2105/AJPH.88.5.828

Rousseau, Ronald (2016). "Citation data as a proxy for quality or scientific influence are at best PAC (probably approximately correct)". Journal of the Association for Information Science and Technology, v. 67, n. 12, pp. 3092-3094.

https://goo.gl/yAnAQZ

https://doi.org/10.1002/asi.23525

Rousseau, Sandra; Rousseau, Ronald (2015). "Metric-wiseness". Journal of the Association for Information Science and Technology, v. 66, n. 11, p. 2389.

https://repository.uantwerpen.be/docman/irua/8eea42/129441. $p d f$

https://doi.org/10.1002/asi.23558

Sivertsen, Gunnar (2010). "A performance indicator based on complete data for the scientific publication output at research institutions". ISSI newsletter, v. 6, n. 1, pp. 22-28.

https://goo.gl/CNzbor

https://www.fct.pt/media/docs/11042014_GSivertsen.pdf

Van-Dalen, Hendrik P.; Henkens, Kène (2012). "Intended and unintended consequences of a publish-or-perish culture: A worldwide survey". Journal of the Association for Information Science and Technology, v. 63, n. 7, pp. 12821293.

http://epc2012.princeton.edu/papers/120181

https://doi.org/10.1002/asi.22636 